\title{
Mineral Exploration in Amapa - Targeting using Magnetic and Gammaspectrometric Regional Survey
}

Aisengart, T.*, South Arm ; Daman, D., Atlas Mining Ltda.; Nascimento, A. , Atlas Mining Ltda.

Copyright 2021, SBGf - Sociedade Brasileira de Geofísica

This paper was prepared for presentation during the $17^{\text {th }}$ International Congress of the Brazilian Geophysical Society held in Rio de Janeiro, Brazil, 8-11 November 2021.

Contents of this paper were reviewed by the Technical Committee of the $17^{\text {th }}$ International Congress of the Brazilian Geophysical Society and do not necessarily represent any position of the SBGf, its officers or members. Electronic reproduction or storage of any part of this paper for commercial purposes without the written consent of the Brazilian Geophysical Society is prohibited.

\begin{abstract}
Mineral exploration in Amapá is being conducted since the mid of last century with good results, the Serra do Navio manganese mine have produced for around 50 years and now have been closed. More recently, there are several junior companies exploring for Iron Ore in this state. Amapá is a state located in the northern region of Brazil. It is the second least populous state and the eighteenth largest by area. Located in the far northern part of the country, Amapá is bordered clockwise by French Guiana to the north, the Atlantic Ocean to the east, Pará to the south and west, and Suriname to the northwest. The project presented in this study is located in the Center-East of the State, distant just 225 Kilometers from the capital Macapá.
\end{abstract}

Due to the complete lack of information on these targets, the decision was made to start all the work through geophysical studies and 3D modeling of the Magnetic Anomalies from the $X Y Z$ data of the Geophysical Project 1069, freely provided by CPRM .

We have reprocessed the data using the new tools available, like the Magnetization Vector Inversion (MVI) and Self Organizing Maps (SOM) to identify exploration targets and we have identified the potential of some projects that are already being explored and new ones with promising results that were verified and are being confirmed by geological mapping. The agreement of the MVI with the field results were exceptionally good and have encouraged us to continue using those techniques and do some higher resolution inversions to follow up work in the highly promising targets obtained by the processing and interpretation of the area. The geological mapping is being conducted in a highly favorable area already confirmed by work in the field that will allow us to program follow up surveys.

\section{Introduction}

The recent availability of airborne geophysical data by the Brazilian Geological Survey (CPRM), allows the regional study of several areas. Combining this availability with the application of inversion and classification algorithms to data from the Amapá State that includes magnetic and gamma spectrometric data, allowed us to identify the most important mineral deposits in this area.
The data used was acquired in 2005/2006 and covers the center-North of the Amapá Sate at an elevation of $100 \mathrm{~m}$ above the terrain and with N-S flight lines with $500 \mathrm{~m}$ separation. This resolution allows a semi-regional study and the methodology used has been demonstrated to be a powerful tool to generate targets as it confirmed known deposits already being explored and indicated new targets.

Through inversion of the geophysical data, we initially created a magnetization model of the full area with low resolution $(1000 \times 2000 \times 200)$ cell sizes (in meters) followed by a higher resolution inversion in a smaller area using cell sizes of $400 \times 400 \times 50$ meters and refined using an even smaller area with resolution of $100 \times 100 \times 50$ meters. In all the inversions the cell size for $\mathbf{Z}$ increases with depth and the stated values were the initial ones used for both the semi-detailed and detailed inversions.

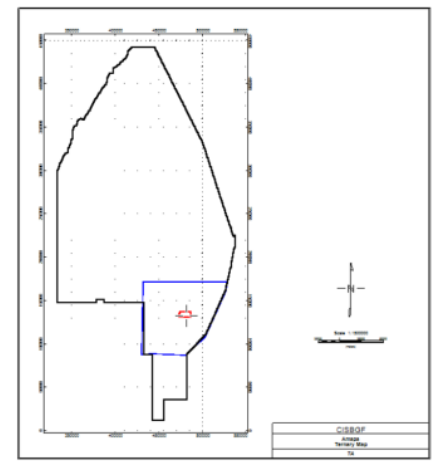

Figure 1: Outline of the survey and low resolution inversion polygon (in black), middle resolution inversion outline (blue) and outline of the high resolution inversion (red)

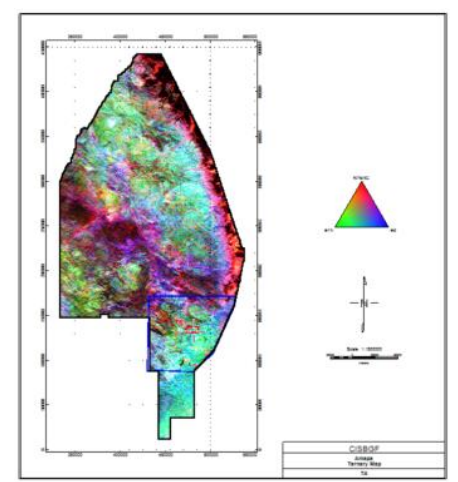

Figure 2: Ternary map of the area from Gamma spectrometric survey (RGB - KthU) 


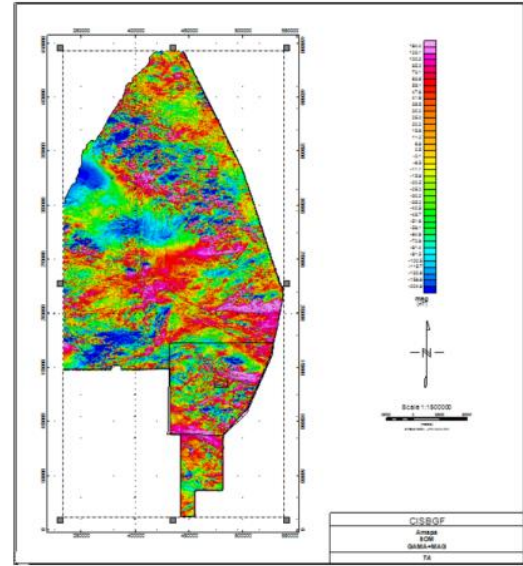

Figure 3: Magnetic anomalous map from the area.

\section{Methodology}

\subsection{Magnetization Vector Inversion (MVI)}

Measuring the magnetic field $B$ in a series of locations $r$ gives the forward equation for the Magnetic Vector (Ellis et al, 2012):

$$
B_{\beta\left(r_{j}\right)}=\sum_{K_{a} a}^{N 3} m_{k_{i} a} \int_{v_{k}} \partial_{\alpha} \partial_{\beta} \frac{1}{\left|r-r_{i}\right|} d r^{3}(1)
$$

Through the discretization of equation (1) is possible to get the equation for the direct problem:

$$
B_{(r)}=\nabla \int_{v} M\left(r^{\prime}\right) \cdot \nabla^{\prime} \frac{1}{|r-r r|} d r^{\prime 3}
$$

That can be simply represented as:

$$
B=\mathrm{Gm}
$$

The Magnetization Vector Inversion problem is to solve for $m$, given $B$. However, is necessary to subject $B$ to regularization conditions to be able to resolve this inverse problem.

The implementation that has been used in this work applied the Tikhonov minimum gradient regularizer (Zhdanov, 2002) to solve the inverse magnetic problem for the magnetic vector by minimizing the difference of the calculated and measured magnetic field. Until recently the physical property used to describe magnetic material in the earth, particularly for inversion, was the susceptibility. The relationship between susceptibility and magnetization is as follows:

$$
\vec{M}=k \vec{H}_{e}
$$

The hypothesis adopted for this description is that the direction of the induced field is aligned with the direction of the Earth's magnetic field, that is the magnetization vector is aligned with the inducing field, the Earth's field direction.

However, the complex nature of rocks demands a more general description of their magnetic properties. Thus, we introduce the anisotropic susceptibility that allows to generalize the scalar susceptibility to a vector susceptibility with three components (kx, ky, kz), with the amplitude of the anisotropic susceptibility being just the scalar susceptibility.

The Magnetization Vector Inversion (MVI) used to develop this paper is based on this effective susceptibility that includes the anisotropic and remnant magnetization as described in equation (5) (Aisengart, 2015, 2017, 2018, 2020):

$$
\vec{M}=\left(\vec{k}+\vec{k}_{R}\right) H_{e}=\vec{k}_{M V I} H_{e}
$$

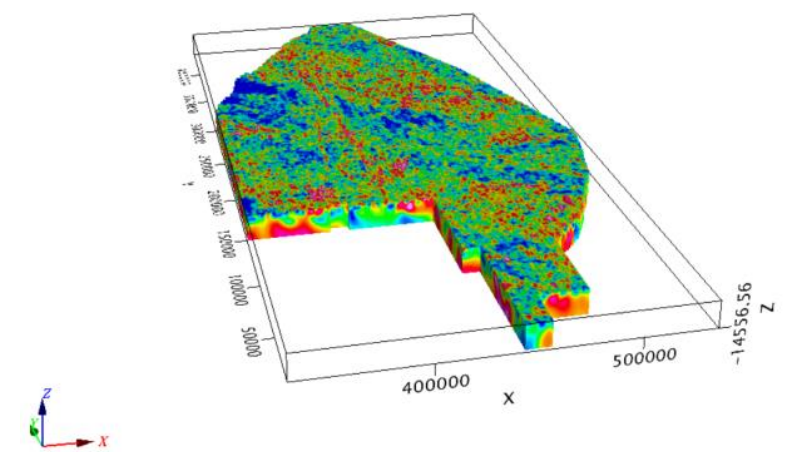

Figure 4: Result of the low resolution MVI for the whole area.

\subsection{Self-Organizing Maps (SOM)}

SOM is an unsupervised classification technique used to analyze and visualize large-scale data. It is based on the principles of measures of quantization vector and this technique has proved itself as an ideal tool to analyze a data set with disparate geophysical parameters. It works based on the preservation of the properties of the bodies and nearby input patterns activate nearby output patterns, generating an automatic classification of the input data.

In this study the Self Organizing Maps (SOM) have been applied to the 2D data combining the radioelements Potassium (K), Thorium (Th) and Uranium (U) with some themes derived from the magnetic data such as the Analytic Signal and the Magnetic anomalous intensity. The 2D map helped to assess and chose key areas of interest that were further investigated in 3D. 


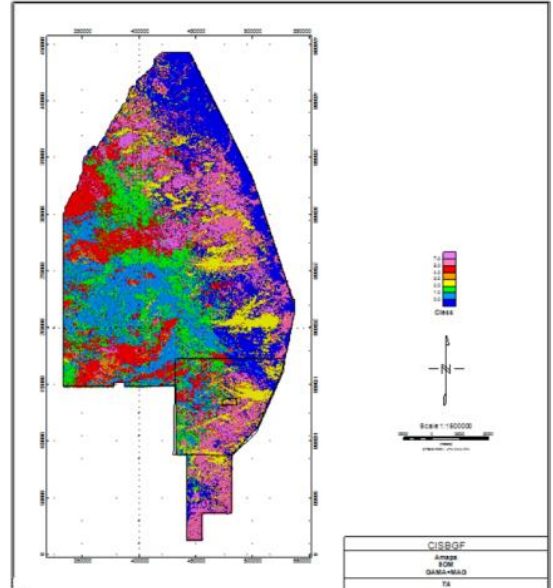

Figure 5: SOM applied to 2D Gammaspectrometric and Magnetic data.

\section{Results}

Due to the complete lack of information on these targets, the decision was made to start all the work through geophysical studies and 3D modeling of the Magnetic Anomalies from the XYZ data of the CPRM Geophysical Project 1069.

Further to the low-resolution inversion of the whole area, a higher resolution inversion in a smaller area was performed, followed by an even higher resolution of a smaller area, containing a previously identified mineralization and a new target area.

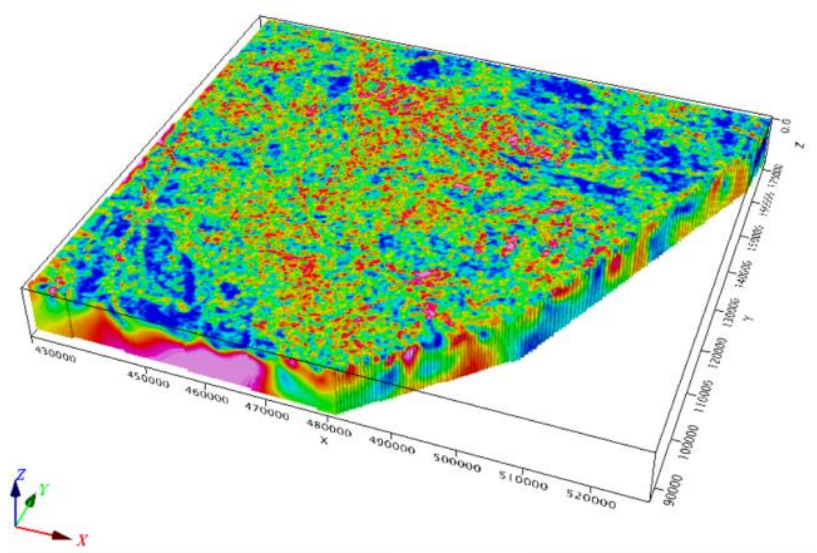

Figure 6: Amplitude voxel result of the higher resolution MVI using the intermediate polygon

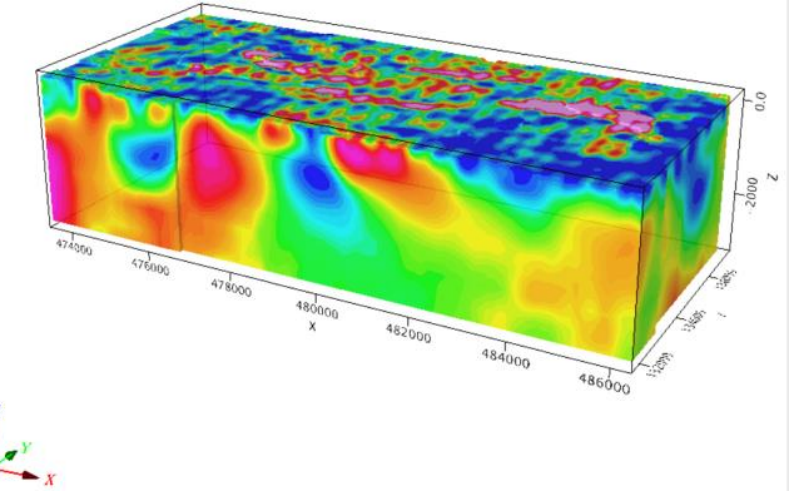

Figure 7: Amplitude voxel result of the even higher resolution $\mathrm{MVI}$ using the small polygon

Using the models generated by the Magnetization Inversion, geological mapping of the smaller polygon was conducted in the field showing an excellent agreement to the observations as can be seen in the Figure 8 , where the mapped outcrops are in accordance with the one pointed in the model.

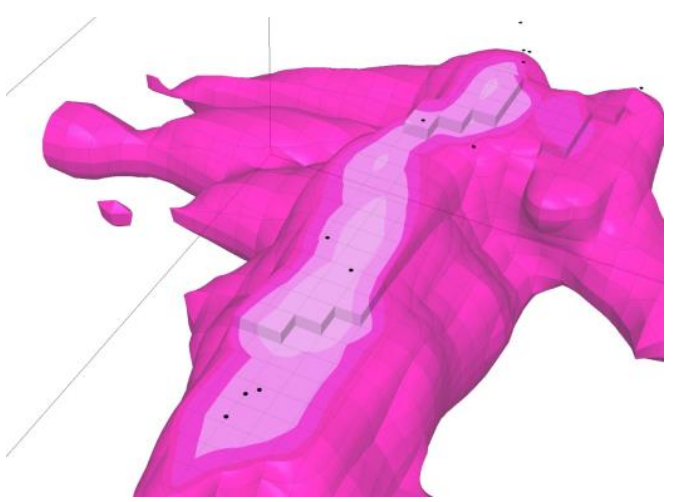

Figure 8: Detail of the Amplitude voxel resulting from MVI and Outcrop points mapped in the field in excellent agreement

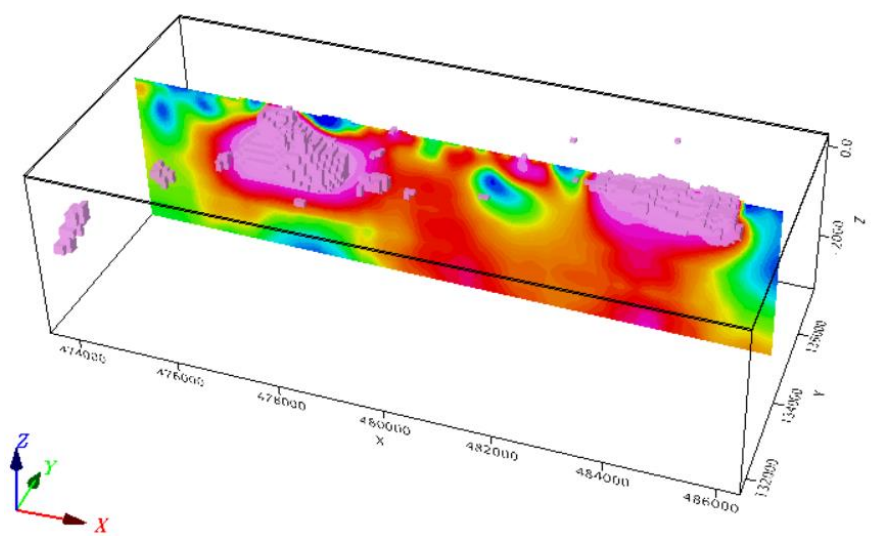

Figure 9: Section from the high-resolution inversion with the previously identified anomaly (left) and the new proposed and verified target (right). 


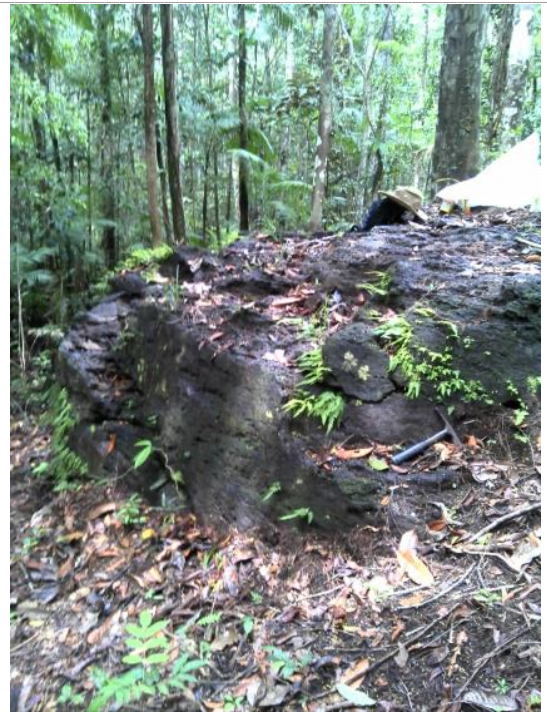

Figure 10: Outcrop verified in the field work coinciding with the high-resolution model indication.

The geological mapping in the field have shown that all the area visited is included, in regional scale mapping (CPRM) in an undifferentiated block composed of granulates of henderbitic, charnocktitic and charnoenderbitic. But it is expected that we will be able to better differentiate, with mapping, some of the lithologies, specially the magnetitic gneiss, following the identified anomalies in this work.

Conclusions

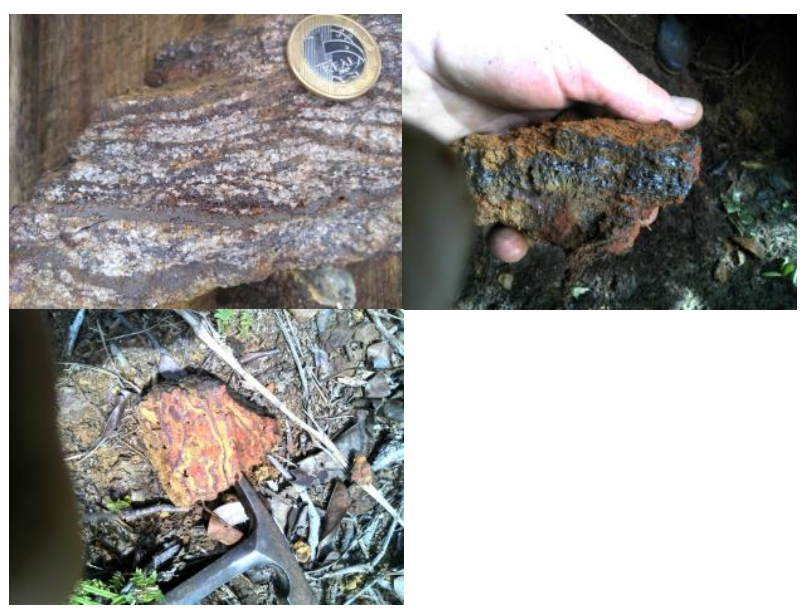

Figure 11- Looking clockwise: Typical magnetitic gneiss from the studied area with alternated bands of quartz and iron oxides (magnetite and hematite);

Enriched alterated gneiss with magnetite and other secundary iron bearing minerals such as goethite.

Al-rich laterite.

\section{Conclusions}

The excellent agreement between the MVI unconstrained model and the geological field mapping is very encouraging and helps to further plan work to delineate and estimate the orebody. By using different resolution models, we were able to pick and refine the targets, up to the sampling limit of the acquisition.

The field work that was conducted further to the data analysis have shown that there is potential to delineate an economical viable ore body, showing as a first estimate a thickness of $50 \mathrm{~m}$ and extension of more than $2 \mathrm{~km}$ of magnetitic gneiss. The results show that at the available resolution, the methodology have again proved to be very potent and stimulates even more the usage of public data for regional exploration.

More work is needed to be able to estimate the economic viability of the available resources such as drilling and ground geophysics using magnetometry and/or gravimetry.

\section{Acknowledgments}

We would like to thank CPRM for providing public access to the airborne geophysical survey data.

\section{References}

Aisengart, T., Ando, J. L, Ferreira, L.C., 2020. Machine Learning Techniques Applied to Carajás Magnetic and Gammaspectrometric Data for Targeting. $2^{\text {nd }}$ Joint SBGfSEG Workshop on Machine Learning, Rio de Janeiro, Brasil

Aisengart, T., Ando, J. L., Batista, L., Ferreira, L.C., 2018. Técnica de self-organizing maps (SOM) aplicada aos modelos regionais de densidade e vetor de magnetização (MVI) da provincia mineral de Carajás. $49^{\circ}$ Congresso Brasileiro de Geologia, Rio de Janeiro, Brasil.

Aisengart, T., Ando, J. L., Barbosa, R. D., Rech, M., Pereira, J.G., 2017. Caracterización de cuerpos intrusivos de la provincia alcalina de Goiás usando inversión geofísica y Self Organizing Maps. XVI Congreso Colombiano de Geologia, Santa Marta, Colombia.

Aisengart, T. 2015. Qualitative and Quantitative Magnetization Vector Inversion applied to the Pirapora Anomaly. 14th International Congress of The Brazilian Geophysical Society, Rio de Janeiro, Brazil.

CPRM Serviço Geológico do Brasil, 2014: Geologia e recursos minerais da Folha Rio Araguari - NA.22-Y-B, Estado do Amapá, Escala 1:250.00 / Lúcia Travassos da Rosa-Costa, Cesar Lisboa Chaves, Evandro Luiz Klein Belém:.159 p. : il. Color.

Ellis, R. G., de Wet, B., MacLeod, I. N., 2012. Inversion of magnetic data for remanent and induced sources. ASEG Extended Abstracts, 1-4.

Zhdanov, M. S., and Portniaguine, O., 2002. 3-D magnetic inversion with data compression and image focusing, Geophysics, 67, 1532-1541.

Zhdanov, M. S; 2002; Geophysical Inverse Theory and Regularization Problems, Methods in Geochemistry and Geophysics. Elsevier Science BV, Amsterdam, Netherlands, v. 36. 